\title{
PENGEMBANGAN CUSTOMER RELATIONSHIP MANAGEMENT
}

\author{
Frans Richard Kodong \\ Jurusan Teknik Informatika UPN "Veteran" Yogyakarta \\ Jl. Babarsari 2 Tambakbayan 55281 Telp (0274) 485323 \\ email : frkodong@gmail.com
}

\begin{abstract}
CRM (Customer Relationship Management) is a computer-based management system or an integrated information system that handles the relationship between the company and its customers with the aim of increasing corporate value in the eyes of its customers. Various research has been done, shows that retaining existing customers is more profitable than attracting new customers. CRM covers all aspects relating to prospects and customers today. CRM is part of an Enterprise Information System. This paper will explain the concept of Information System at the Company, CRM and e-CRM technology based on web. One application of the above technology is the application of CRM in enterprise applications for the property.

Keywords : CRM, Web, Enterprise Informasion System.

CRM (Customer Relationship Management) adalah sistem manajemen berbasis komputer atau sebuah sistem informasi terintegrasi yang menangani hubungan antara perusahaan dengan pelanggannya dengan tujuan meningkatkan nilai perusahaan di mata para pelanggannya. Berbagai riset yang telah dilakukan, menunjukan bahwa mempertahankan pelanggan lama lebih menguntungkan daripada menarik pelanggan baru. CRM melingkupi semua aspek yang berhubungan dengan calon pelanggan dan pelanggan saat ini. CRM merupakan bagian dari suatu Enterprise Information System. Pada makalah ini akan dijelaskan konsep Sistem Informasi pada Perusahaan, CRM dan teknology e-CRM yang berbasis web. Salah satu penerapan teknologi diatas adalah aplikasi CRM pada aplikasi untuk perusahaan property.

Kata kunci : CRM, Web, Enterprise Informasion System.
\end{abstract}

\section{PENDAHULUAN}

Dalam suatu perusahaan modern, Teknologi Informasi merupakan salah satu faktor penentu keberhasilan dalam meraih apa yang menjadi tujuan perusahaan tersebut. Penggunaan sistem komputer sudah menjadi kebutuhan sehari hari, sebut saja penggunaan dari software Word Processor, Spreadsheet, internet, e-mail dan aplikasi komputer lainnya, namun untuk dapat mendukung rencana strategis perusahaan tidaklah cukup dengan menggunakan sistem komputer seperti diatas. Konsep Enterprise Information System, salah satunya CRM perlu di terapkan dalam perusahaan tersebut jika ingin mencapai tujuannya.

Pengembangan CRM dapat dilakukan melalui tahapan analisis, perancangan, implementasi dan pemeliharaan, yang dikenal dengan SDLC (System Development Life Cycle). Teknologi yang digunankan adalah pemrograman web (PHP), mengunakan Relational Database Management System MySQL.

Untuk mengetahui kinerja perusahaan setelah mengimplementasikan CRM, dapat diukur dengan menggunakan economic profit indicator seperti ROI (Return on Investment), IRR (Internal Rate of Return),

\section{CRM (Customer Relationship Management).}

Sistem Informasi Enterprise pada umumnya merupakan sistem informasi berbasis komputer pada perusahaan yang menawarkan kualitas layanan yang tinggi, yang berhubungan dengan basisdata dan mampu mendukung kegiatan perusahaan. Sistem Informasi Enterprise menyediakan platform teknologi yang memungkinkan organisasi untuk mengintegrasikan dan mengkoordinasikan proses bisnis mereka.

CRM merupakan bagian dari Sistem Informasi Perusahaan, adalah suatu strategi bisnis yang menggunakan teknologi informasi untuk menghasilkan perusahaan yang berkompeten, terpercaya dan terintegrasi dengan pelanggan berdasarkan sisi pelanggan sehingga semua 
proses dan interaksi dengan pelanggan membantu terpeliharanya dan meningkatkan hubungan relasi yang menguntungkan. CRM didefinisikan sebagai strategi sales, marketing dan service yang terintegrasi. CRM adalah proses dinamis dalam mengatur hubungan antara pelanggan dengan perusahaan agar para pelanggan dapat memilih untuk tetap melanjutkan hubungan saling menguntungkan secara komersial dan untuk mengantisipasi agar hubungan tersebut tidak menjadi tidak menguntungkan perusahaan (Reynald, 2011).

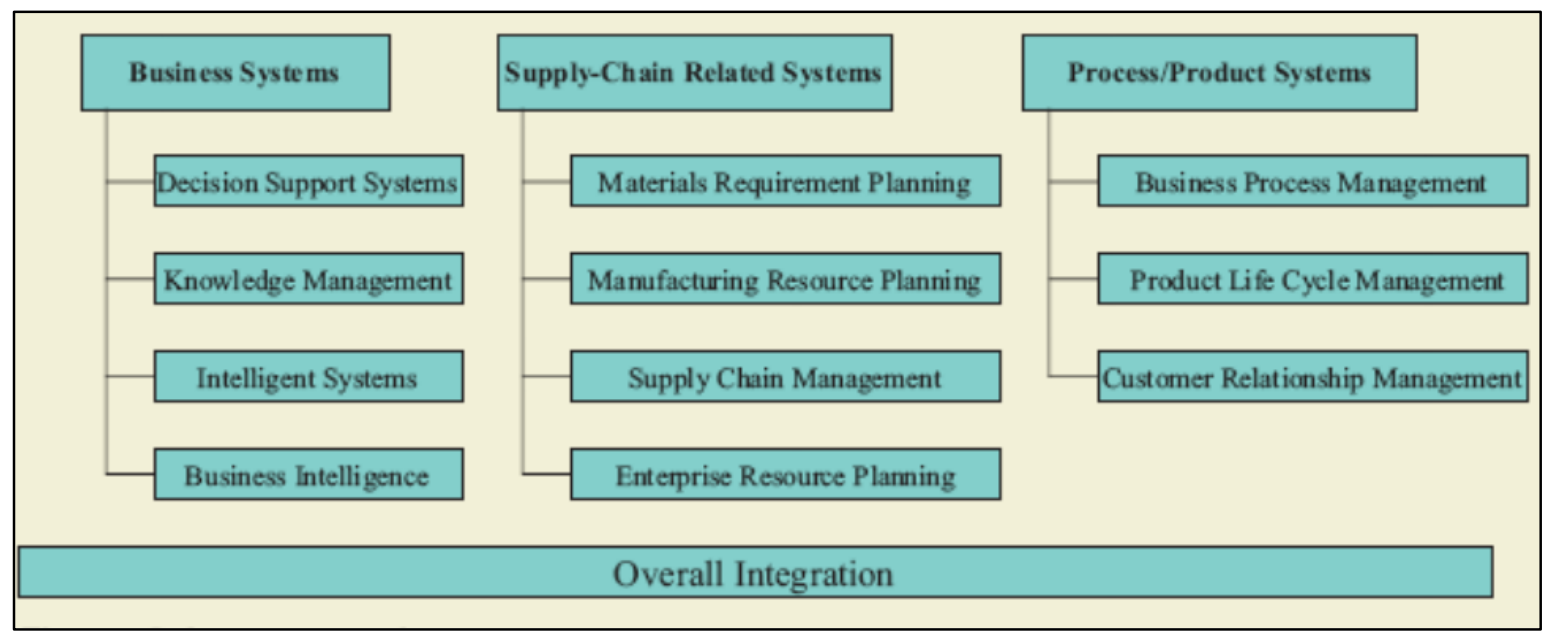

Gambar 1. Esential of Interprise Systems (Windi dan Novianto, 2011)

CRM merupakan bagian dari Sistem Informasi Perusahaan, adalah suatu strategi bisnis yang menggunakan teknologi informasi untuk menghasilkan perusahaan yang berkompeten, terpercaya dan terintegrasi dengan pelanggan berdasarkan sisi pelanggan sehingga semua proses dan interaksi dengan pelanggan membantu terpeliharanya dan meningkatkan hubungan relasi yang menguntungkan. CRM didefinisikan sebagai strategi sales, marketing dan service yang terintegrasi (Kalakota dan Robinson, 2001). CRM adalah proses dinamis dalam mengatur hubungan antara pelanggan dengan perusahaan agar para pelanggan dapat memilih untuk tetap melanjutkan hubungan saling menguntungkan secara komersial dan untuk mengantisipasi agar hubungan tersebut tidak menjadi tidak menguntungkan perusahaan (Bergeron, 2002).

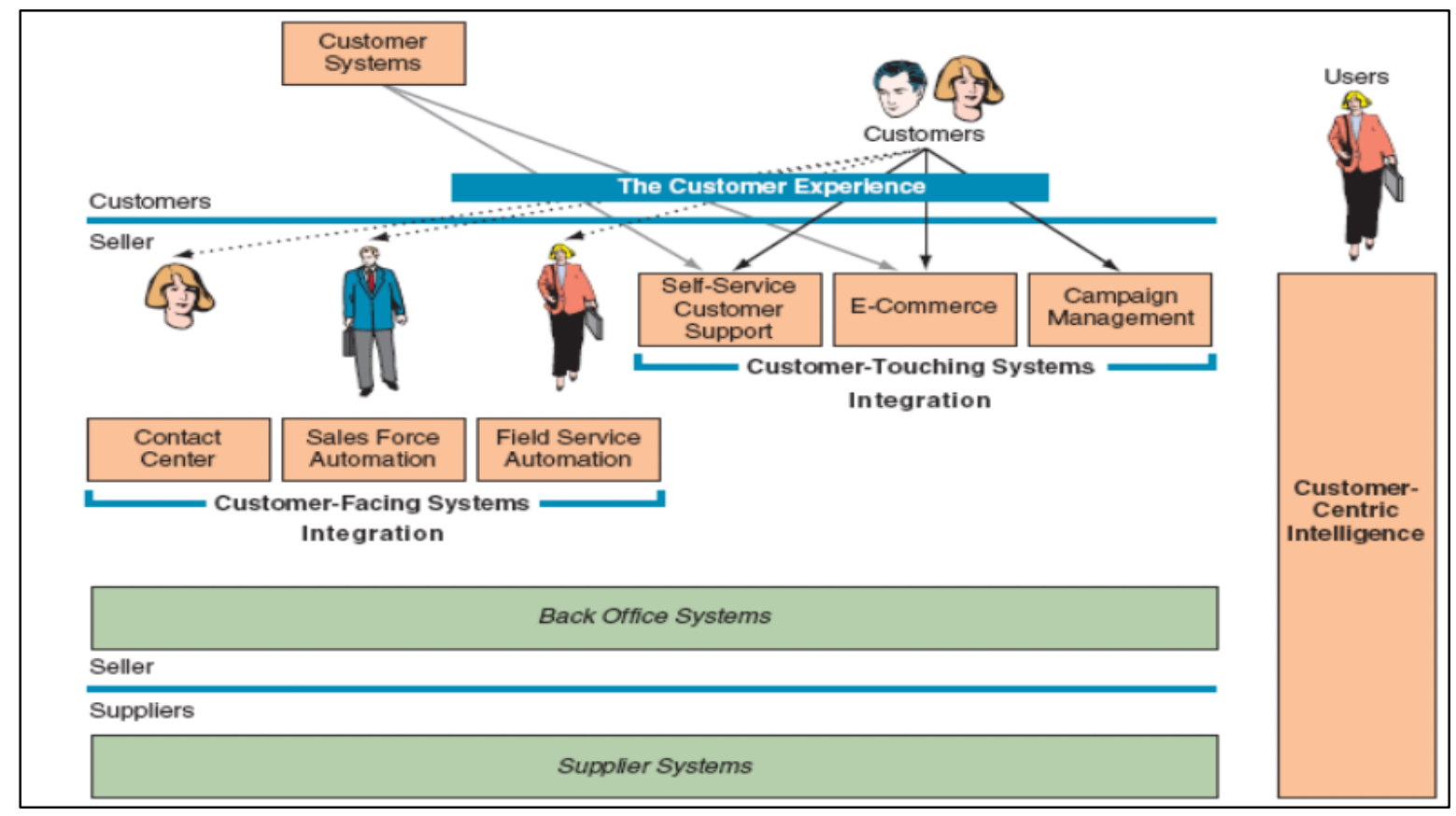

Gambar 2. Customer Relationship Management (Windi dan Novianto, 2011) 
CRM memiliki 3 fase (Reynald, 2010), yaitu :

a) Menjaring pelanggan baru (Acquire).

Perusahaan mendapatkan pelanggan baru dengan mempromosikan keunggulan produk dan jasa perusahaan. Perusahaan mendemonstrasikan bagaimana mereka menegaskan kembali lingkup/batasan performa industri dengan menghargai kenyamanan dan inovasi. Proporsi nilai bagi pelanggan adalah penawaran dari produk superior yang ditempa oleh pelayanan yang memuaskan. Mendapatkan pelanggan baru menuntut tingkatan yang serupa dengan determinasi. Strategi untuk akuisisi yang berhasil membutuhkan perencanaan yang benar-benar matang guna menyusun penjualan yang kaya, tinggi, dan terintegrasi, dan mendukung pengalaman bagi pelanggan.

b) Meningkatkan kemampuan untuk menghasilkan keuntungan dari pelanggan yang telah ada (Enhance).

Perusahaan meningkatkan hubungan pelanggan dengan memberikan perhatian yang memuaskan dalam up-selling dan cross-selling, yang dengan cara demikian juga memperdalam dan memperluas hubungan tersebut. Proporsi nilai bagi pelanggan adalah penawaran dari kenyamanan yang lebih besar dengan biaya yang rendah (one-stop shopping). Perusahaan dapat membuktikan komitmen mereka pada basis keseharian dengan menyediakan waktu untuk mendengarkan keluhan/pendapat pelanggan dan dengan mengembangkan fokus pelayanan mereka.

c) Mempertahankan pelanggan yang menguntungkan untuk kelangsungan hidup (Retain).

Retensi berfokus pada kemampuan adaptasi pelayanan mengirimkan apa yang dikehendaki pelanggan dan bukanlah yang dikehendaki pasar. Proporsi nilai bagi pelanggan adalah penawaran dari suatu hubungan yang proaktif yang bekerja pada bidang yang menjadi ketertarikan/minat pelanggan yang paling baik. Alasan dibalik strategi ini adalah sederhana : jika perusahaan ingin mendapatkan untung, pertahankan pelanggan yang baik.

Ada 3 jenis aplikasi CRM (Reynald, 2010), antara lain ; :

a) Operational CRM

Operational CRM adalah pengelolahan secara otomatis dari proses bisnis secara terintegrasi dan horizontal termasuk customer touch-points dan integrasi front-back office.

b) Analytical CRM

Analytical CRM adalah analisis data yang diperoleh dari Operational CRM dengan memanfaatkan tools dan software untuk mendapatkan pemahaman yang lebih baik mengenai perilaku pelanggan atau kelompok pelanggan.

c) Collaborative CRM

Collaborative CRM adalah seperangkat aplikasi dari pelayanan kolaborasi termasuk e-mail, e-communities, publikasi personal dan alat lainnya yang sejenis yang dirancang untuk memfasilitasi interaksi antara pelanggan dengan perusahaan.

Beberapa manfaat dari sistem CRM bagi perusahaan adalah sebagai berikut ((Reynald, 2010):

a) Customer focus

Perusahaan bersedia memandang proses pembelian dari pandangan pelanggan, dengan memperhatikan perasaan pelanggan dan memperlakukan informasi pelanggan dengan baik.

b) Customer relation

Mempertahankan pelanggan dan membangun loyalitas pelanggan adalah tujuan utama dari pendekatan CRM. Biaya untuk memperoleh pelanggan baru mungkin tinggi. Pepatah bisnis lama mengatakan "Diperlukan biaya enam kali lebih besar untuk memperoleh pelanggan baru daripada mempertahankan pelanggan lama". Banyaknya jumlah pelanggan yang bertahan pada suatu perusahaan dapat meningkatkan pendapatan, dan dalam banyak kasus juga bisa mengurangi biaya.

c) Share of customer 
Perusahaan selalu ingin menyenangkan pelanggan secara langsung dimana sebagian pelanggan juga menginginkan agar perusahaan menawarkan sesuatu yang lain dari yang pernah mereka beli sebelumnya.

Hal ini dapat dilakukan dengan dua cara yaitu :

i. Cross selling yaitu pemasaran produk lengkap pada pelanggan lama.

ii. Up selling yaitu pemasaran produk yang mempunyai nilai yang lebih tinggi pada pelanggan baru dan lama.

d) Long-term profitability

Apabila perusahaan dapat berfokuskan pada pelanggan, mempertahankan pelanggan loyal dan meningkatkan jumlah pelanggan maka perusahaan kemungkinan besar akan memperoleh dan bahkan meningkatkan keuntungan jangka panjang.

e) Continuity

Kontinuitas diperoleh dari hubungan dengan penjual yang sama sehingga mempermudah proses pembelian pelanggan.

f) Contact point

Pembeli ingin menjadi pelanggan tetap karena mereka ingin berbisnis dengan perusahaan yang menyediakan konsistensi kualitas produk dan jasa. Oleh karena itu, sistem CRM harus memungkinkan pelanggan untuk berhubungan dan berkomunikasi dengan perusahaan. Jadi contact point ini adalah metode interaksi seperti melalui telepon, e-mail, poin pembelian dan sebagainya.

g) Personalization

Perusahaan harus mengetahui nama pelanggan, rutinitas pembelian pelanggan sehingga dapat memprediksi kebutuhan pelanggan yang bervariasi dengan baik. Dengan teknologi informasi yang tepat, pelanggan dapat memperoleh manfaat dari jasa personalisasi.

Tujuan dari kerangka bisnis CRM (Reynald, 2010), meliputi :

a) Menggunakan hubungan yang telah ada untuk menambah pendapatan. Perusahaan memandang pelanggan secara luas untuk memaksimalkan hubungan diantara mereka sehingga dapat meningkatkan profitabilitas perusahaan dengan mengidentifikasi, menarik dan mempertahankan pelanggan yang potensial.

b) Menggunakan informasi yang terintegrasi untuk pelayanan yang terbaik.

c) Dengan menggunakan informasi pelanggan untuk memberikan pelayanan yang lebih baik bagi kebutuhannya, maka pelanggan tidak perlu berulang kali meminta informasi yang mereka butuhkan kepada perusahaan sehingga menghemat waktu dan mengurangi frustasi mereka.

d) Memperkenalkan saluran proses dan prosedur yang konsisten dan dapat ditiru. Dengan perkembangan saluran komunikasi bagi pelanggan, maka semakin banyak karyawan yang terlibat dalam transaksi penjualan, sehingga perusahaan harus memperbaiki konsistensi proses dan prosedural.

Jadi tujuan CRM adalah untuk memperoleh hubungan dengan pelanggan yang dapat memberikan keuntungan yang signifikan bagi perusahaan. Untuk mencapai tujuan tersebut, bagian pemasaran, penjualan dan pelayanan harus bekerjasama lebih erat dalam sebuah teamwork dan saling berbagi informasi.

\section{Keberhasilan CRM.}

Untuk mengetahui tingkat keberhasilan implementasi dari CRM dapat meggunakan economic profit indicator yang telah dicapai oleh suatu perusahaan, seperti IRR (Internal rate of Return), ROI (rate of return), dan analisa loss and profit performance. Beberapa contoh keberhasilan implementasi CRM ; Adobe System's North America, dapat mencapai $16 \%$ IRR setelah menginvestasikan CRM. Perusahaan tersebut telah merealisasikan peningkatan productivity, peningkatan pendapatan dan lebih efisiensi dalam penggunaan waktu. (www.sap.com, 2010)

\section{CRM perusahaan Property.}

Dari hasil analisis yang dilakukan pada perusahaan Property dapat dirancang CRM sebagai berikut ; 
Aplikasi CRM perusahaan property memiliki empat buah entitas external yaitu admin, member, user dan customer service. Dalam hal ini admin memegang pengendalian penuh untuk mengolah sistem yang dibuat. Member bisa mendapatkan informasi dari sistem berupa property, profile, pemesanan / pembelian, progress, komplain, komentar, serta penjadwalan. Customer service dapat mengakses informasi dari sistem yaitu property, member, profile member, progress, komplain, komentar dan penjadwalan. Sedangkan user biasa hanya dapat mengakses info property / news. Dari analisis yang dilakukan, diperoleh DFD level 0 sebagai berikut yang ditunjukan pada gambar 3 .

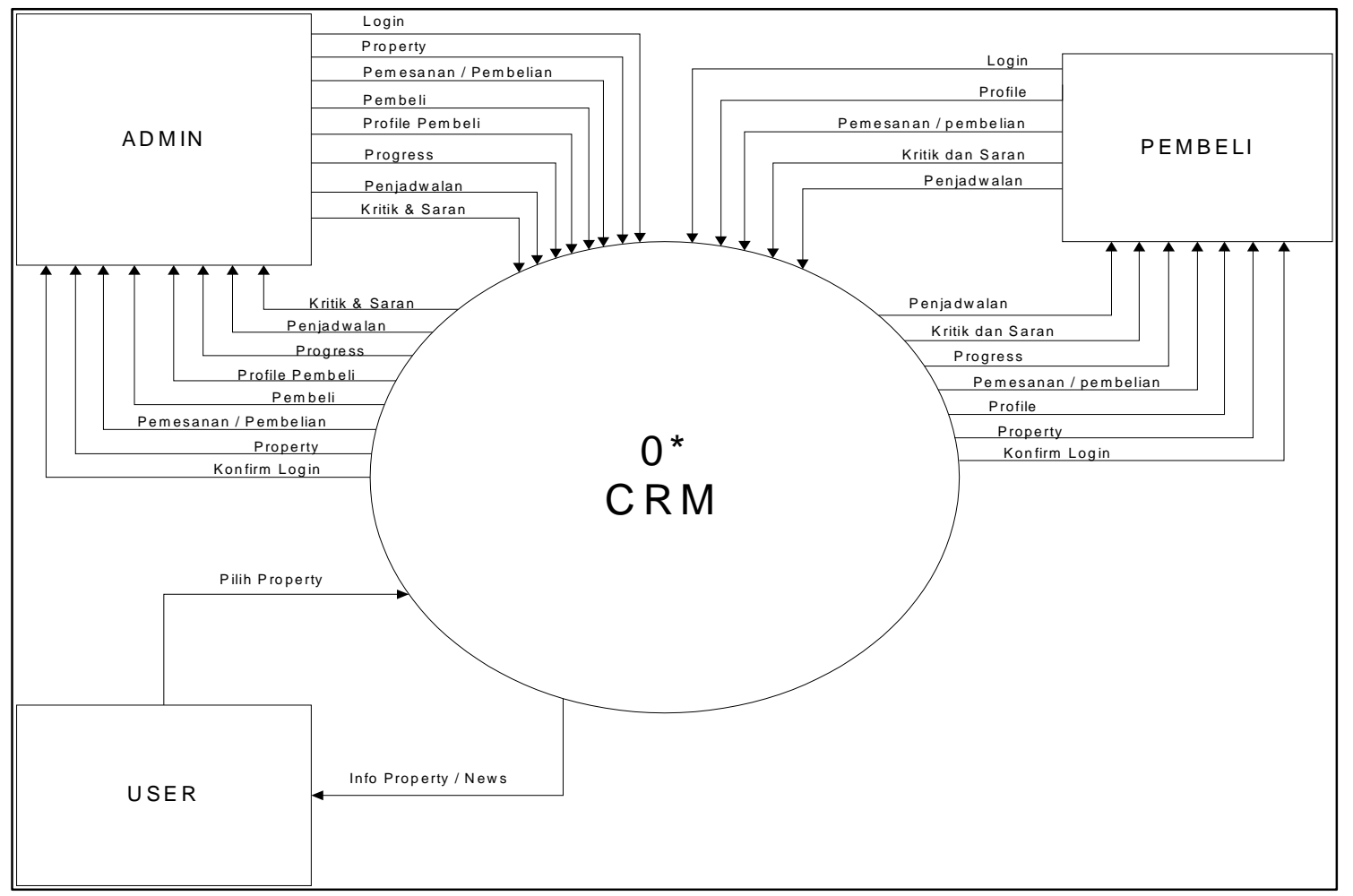

Gambar 3. DFD Level 0 Aplikasi CRM pada Perusahaan Property

Context Diagram diatas dapat di bagi menjadi 4 proses yang menggambarkan aliran data dan interaksi antara sistem dengan pengguna. Proses yang terjadi yaitu :

1. Proses Layanan Admin, merupakan proses yang dapat dilakukan oleh admin. Dalam sistem ini, admin dapat mengolah semua isi atau data yang ada dalam sistem. Admin merupakan pengguna yang mempunyai hak akses paling tinggi dalam sistem. Admin juga bisa menjadi user biasa, pembeli maupun customer service. Jadi, admin adalah orang yang benar - benar dapat dipercaya. Admin bertanggung jawab penuh atas data yang ada dalam sistem ini. Fungsi dari admin adalah sebuah solusi pemecahan permasalahan dalam lingkup pengolahan data pada sistem ini. Misalnya dalam pengisian data pelanggan dalam sistem terdapat kesalahan dan perlu diperbaiki, maka seorang admin sangat dibutuhkan untuk memperbaiki kesalahan yang terjadi.

2. Proses Layanan Customer service, merupakan proses yang ditujukan bagi petugas personalia atau customer service(selanjutnya disebut CS), proses ini mirip dengan proses pada admin. Dalam sistem ini CS merupakan bagian yang berhubungan langsung dengan pelanggan/pembeli, dimana jika pembeli/pelanggan membutuhkan informasi mengenai produk yang ditawarkan dapat langsung berinteraksi dengan petugas personalia.

3. Proses Layanan Pembeli, merupakan sebuah sistem yang diciptakan untuk melayani para pembeli/pelanggan di perusahaan, dimana sistem CRM ditujukan kepada mereka. Pembeli diwajibkan login terlebih dahulu, kemudian pembeli dapat mengetahui perkembangan melalui progress pembangunan rumah mereka serta 
mengetahui penjadwalan untuk melihat perkembangan rumah mereka. Pembeli juga dapat memberikan komplain, komentar, serta kritik dan saran.

4. Proses Layanan User, Layanan user adalah sistem dimana user biasa (calon pembeli) dapat mengetahui mengenai informasi perumahan yang disediakan perusahaan. User juga dapat memesan property secara online dari web tersebut dengan mengisi form pemesanan.

Secara keseluruhan struktur logika dari basis data dapat digambarkan secara grafik dengan menggunakan Entity Relationship Diagram (ERD). Rancangan ERD dalam sistem ini dapat dilihat pada gambar 4 .

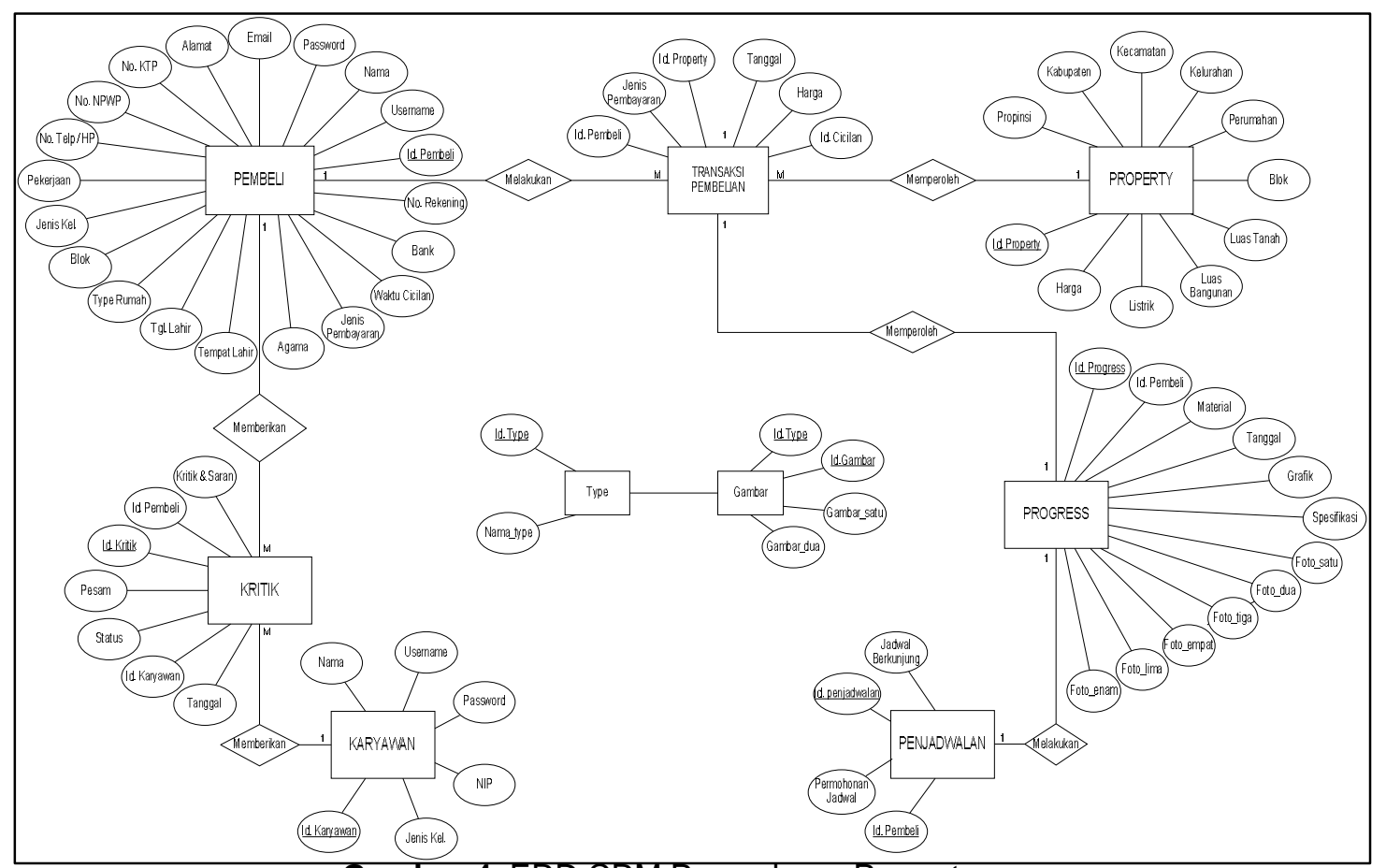

Gambar 4. ERD CRM Perusahaan Property

Adapun beberapa hasil implementasi dapat dilihat pada gambar-gambar dibawah ini

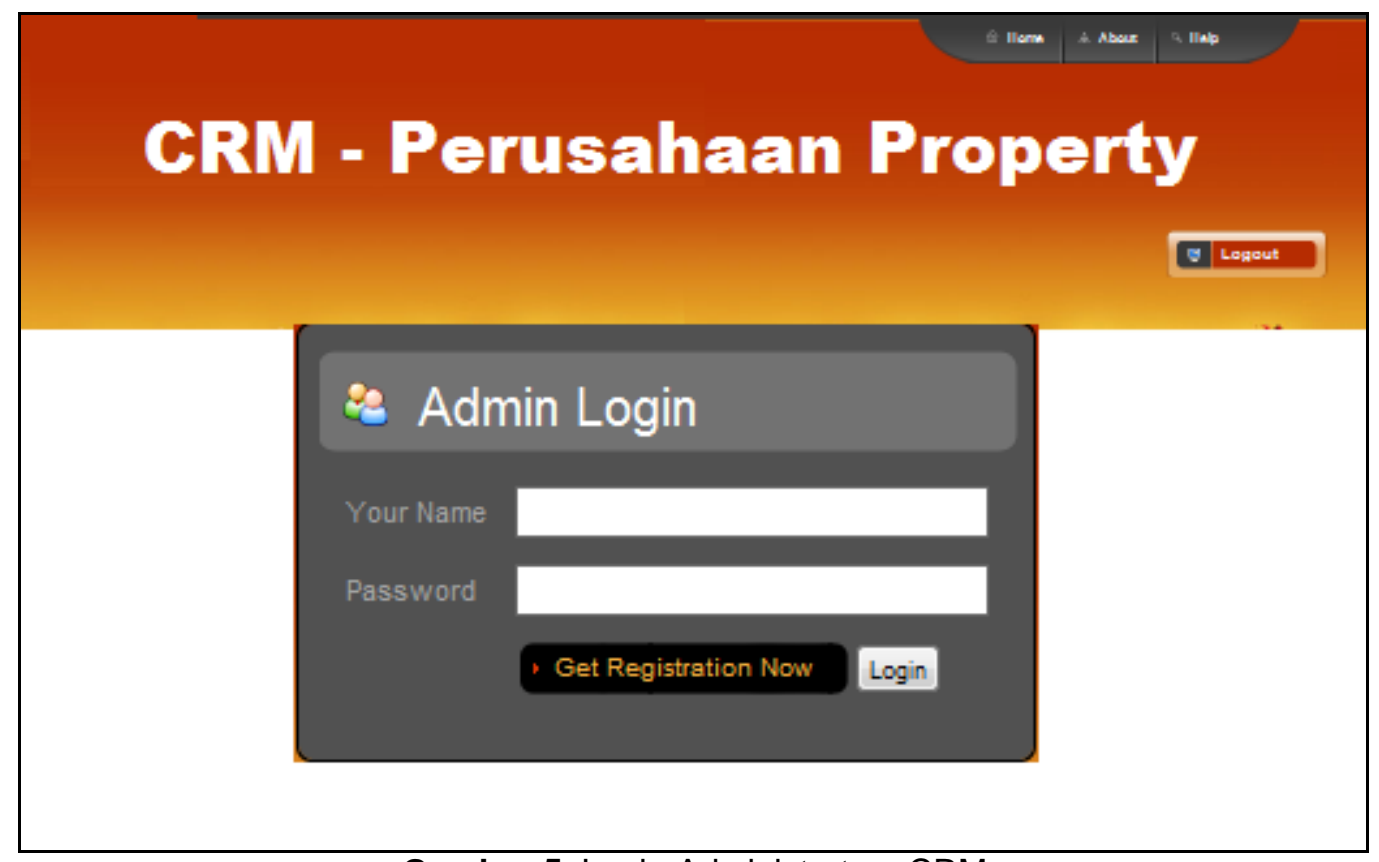

Gambar 5. Login Administratyor CRM 


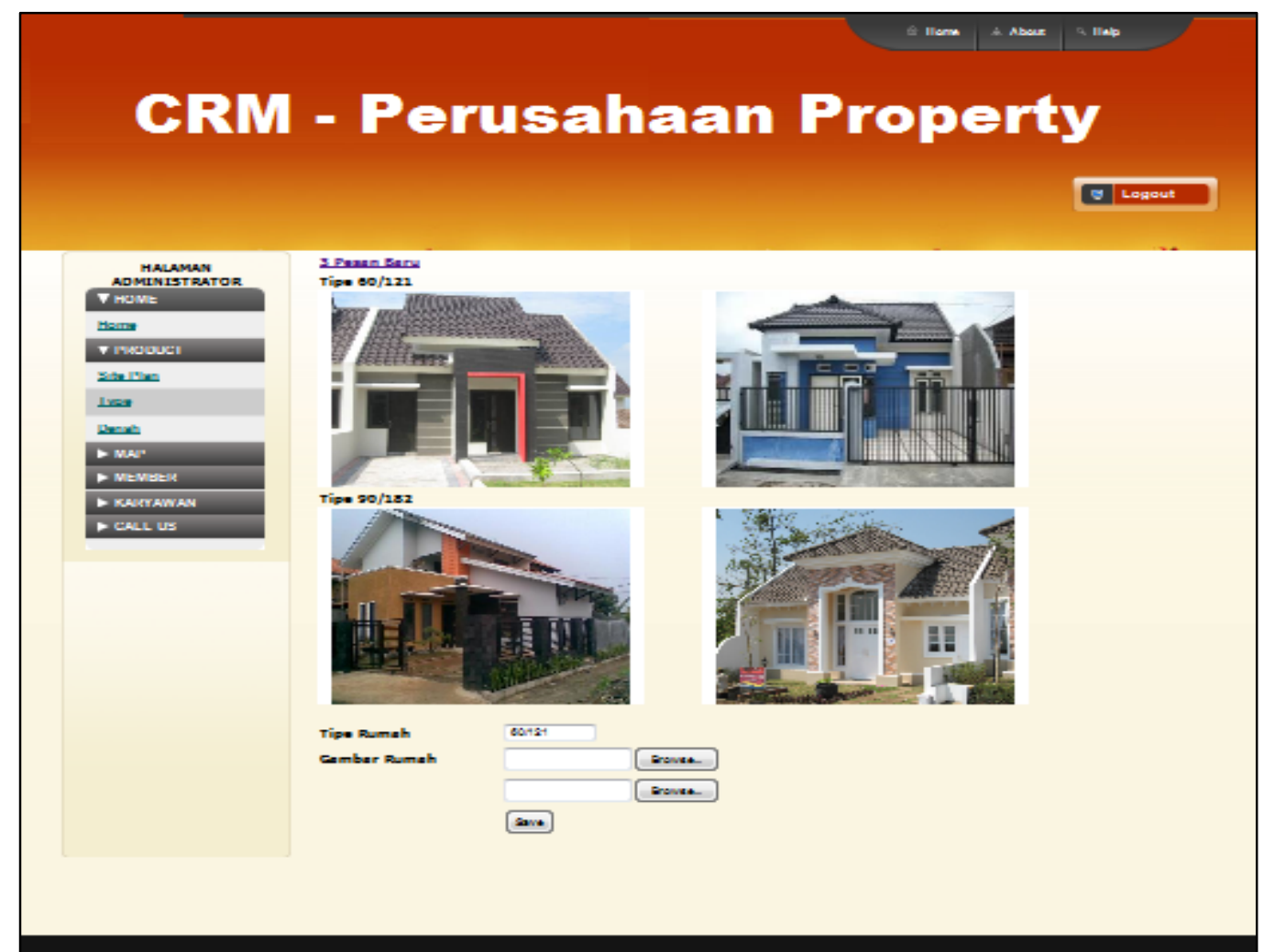

Gambar 6. Tampilan Product Property

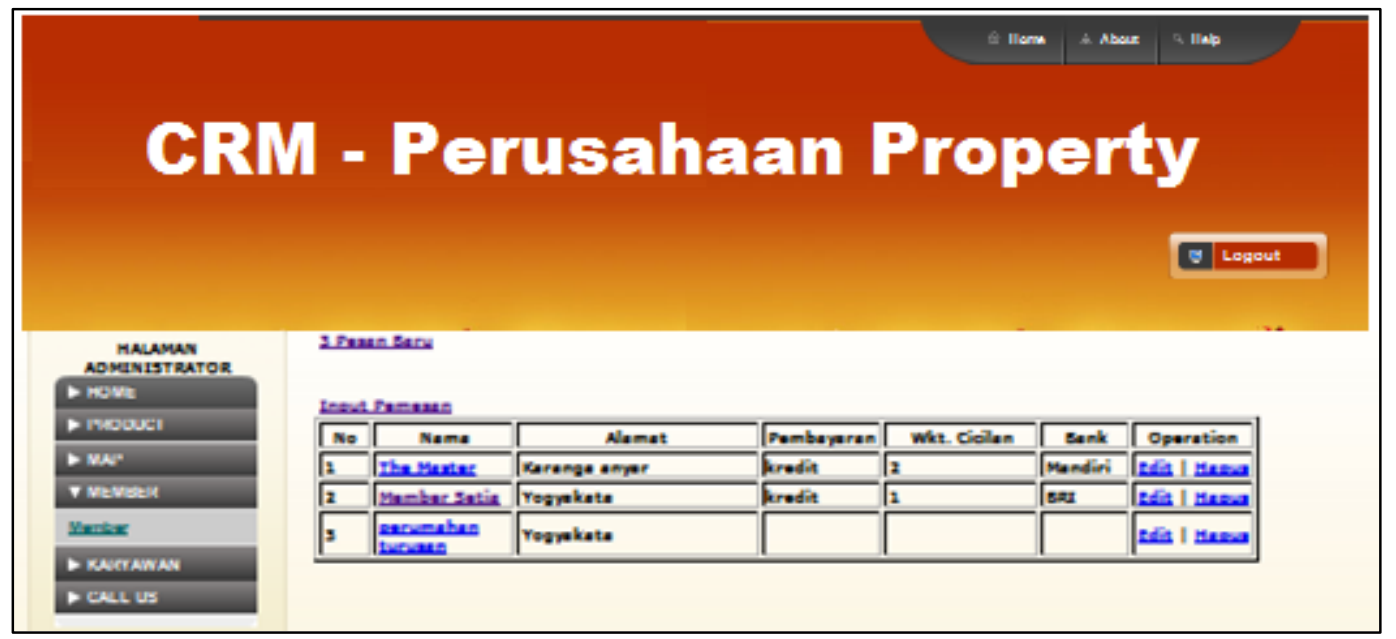

Gambar 7. Tampilan Form Members 


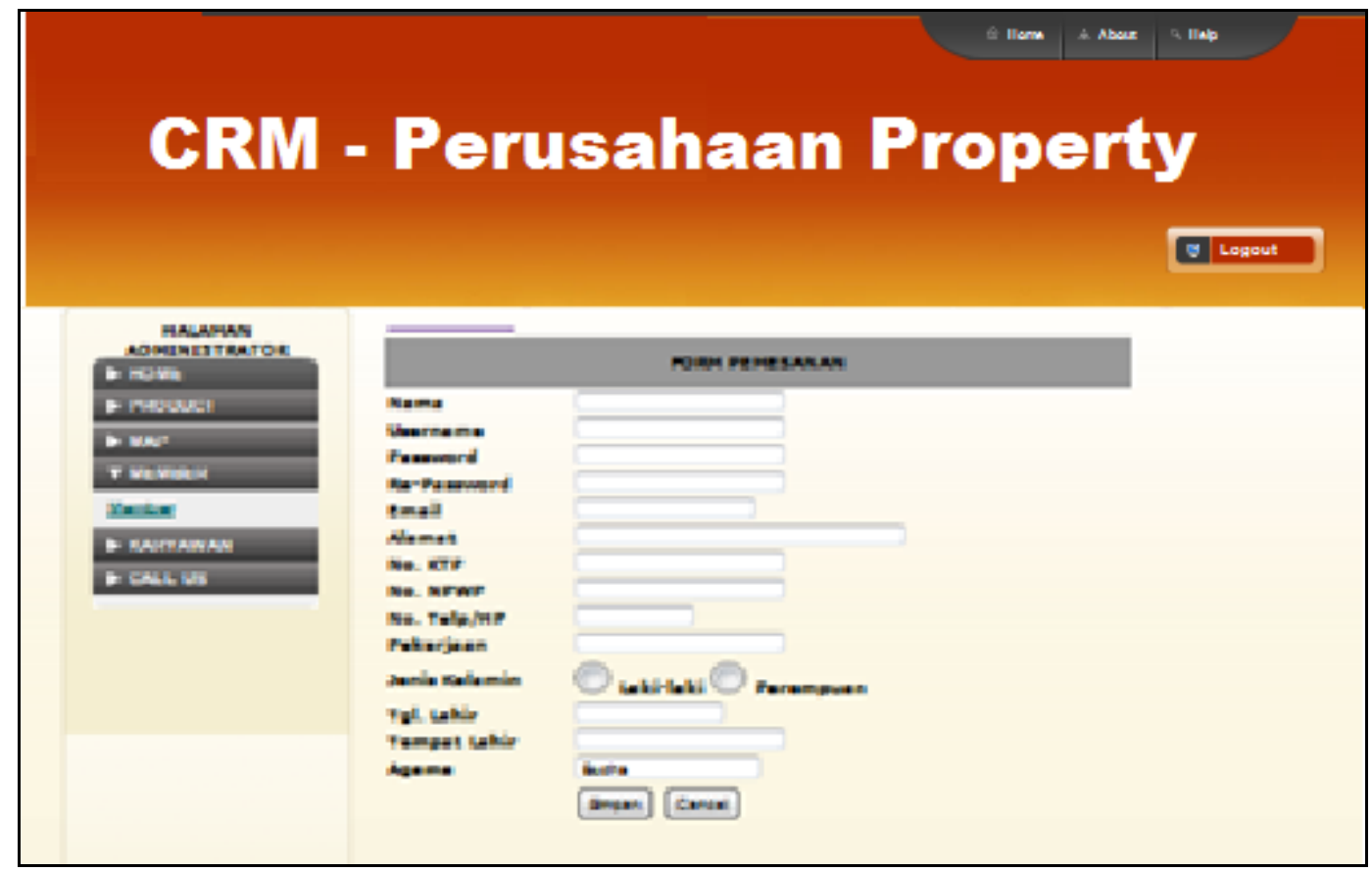

Gambar 8. Tampilan Form Members - proses pemesanan

\section{PENUTUP}

Setelah melakukan kajian konsep dasar, tahapan pengembangan, dan melakukan pengamatan implementasi dari CRM, didapatkan hasil sebagai berikut :

a. Dengan tahapan pengembangan sistem SDLC, dapat dibangun CRM Perusahaan Property, yang diharapakan dapat menjaga relasi, interaksi terhadap pelanggan agar mendapat keuntungan yang signifikan bagi perusahaan.

b. Setelah melakukan Implementasi CRM, Perusahaan dapat melakukan analisis ekonomi untuk mengetahui kinerjanya, menggunakan beberapa metode seperti ROI dan IRR.

\section{DAFTAR PUSTAKA}

Alex Breznev P., Novianto Kuswandi, Windi Novianti, 2010, Customer Relationship Management, URL : http://www.slideshare.net/windynovianti, di akses pada 15 Januari 2011

Bergeron Bryan, 2002, Essentials of Customer Relationship Management, Wiley \& Son Inc,New York

Peranginan, K. ,2006, Aplikasi Web Dengan PHP dan MySQL, Andi, Yogyakarta

Reynald Dwi Kristianto ,2010, Customer Relationship Management, Teknik Informatika UPN "Veteran" Yogyakarta

SAP, 2010, Customer Relationship Management, URL http://www.sap.com, di akses pada 20 Januari 2011

WIKIPEDIA, Customer Relationship Management, URL http://en.wikipedia.org/wiki/Customer relationship management, di akses pada 20 Januari 2011 